\title{
Optimal Executive Compensation Dispersion and Product Market Structure
}

\author{
Ding Chen ${ }^{1,2^{*}}$, Shin-Hwan Chiang ${ }^{3}$, Yutong Li ${ }^{1}$ \\ ${ }^{1}$ School of Economics and Management, Xi'an Shiyou University, Xi'an, China \\ ${ }^{2}$ Economics Department, University of Kansas, Lawrence, USA \\ ${ }^{3}$ Economics Department, York University, Toronto, Canada \\ Email: *chending1981@163.com
}

How to cite this paper: Chen, D., Chiang, S.-H. and Li, Y.T. (2018) Optimal Executive Compensation Dispersion and Product Market Structure. American Journal of Industrial and Business Management, $\mathbf{8}$, 2052-2060.

https://doi.org/10.4236/ajibm.2018.89135

Received: August 15, 2018

Accepted: September 19, 2018

Published: September 30, 2018

Copyright $\odot 2018$ by authors and Scientific Research Publishing Inc. This work is licensed under the Creative Commons Attribution International License (CC BY 4.0).

http://creativecommons.org/licenses/by/4.0/

\section{Open Access}

\begin{abstract}
Executive compensation is considered as one of the most crucial issues for the corporate governance. The proper executive compensation dispersion can be employed to motivate the top managers and then to boost the firm performance, but the definition of "proper" varies in the existing literature. The bigger dispersion is better for firm performance based on Tournament Theory but smaller one is better according to some other theories. In this paper, we try to theoretically study the optimal executive compensation by considering the internal and external situation of the firm at the same time, especially the influence of product market. We find the optimal compensation dispersion will increase (decrease) if more (less) firms enter the market when the cost of sabotage increases more rapidly than the cost of effort, vice versa. The findings imply the firm should increase (decrease) the compensation dispersion if the intensity of competition in product market decreases (increases) when sabotage is expensive and the firm should increase (decrease) the compensation dispersion if the intensity of competition in product market increases (decreases) when sabotage is cheap.
\end{abstract}

\section{Keywords}

Wage Dispersion, Market Structure, Tournaments, Executive Compensation

\section{Introduction}

Before the 1980s, enterprises in China were state owned. Production objectives and product prices were set by state. Enterprise managers were evaluated and compensated for following government orders and subservience to political dogma (Mengistae and $\mathrm{Xu}, 2004$ ) [1]. Wages paid to enterprise workers and 
managers were centrally determined, primarily on the basis of education and seniority (Dong, 2005) [2]. Wage differences between organizational ranks were minimal and more symbolic than substantive, reflecting an egalitarian ideology (Korzec, 1992) [3].

In the wake of China's transition to a more market-oriented economy, the product market is changing dramatically during the recent thirty years of the reformation period. Labor and capital are allowed to move with less constraint, which makes the resource allocation become more efficiently. Consequently, the competition of product market becomes more obvious and fierce.

Meanwhile, there are strong evidences that wage dispersion has increased among enterprise workers in China (Appleton et al., 2005; Dong, 2005) [2] [4]. Many findings suggest the wage dispersion could be considered as an incentive mechanism to motivate the executives to make more effort to increase the firm performance since the executive pay structure in China has started to resemble that seen in developed market economies. For example, compensation data on 17,178 executives from 1386 publicly listed firms in China during 1999-2006 are used to show that executive pay dispersion is positively related to the variation in firm performance while pay distribution skews toward the top of the firm (Lin et al., 2011) [5].

It seems the pay structure changes when the product market structure changes, which implies there may be some relationship between them and it is important to understand the change of executive compensation in China. But this issue is not sufficiently studied in the existing literature which is the basic reason why we would like to analyze this relationship.

This paper is organized as follows. Section 2 reviews the literature on the relationship between executive compensation and firm performance with market structure considered. Section 3 presents our theoretical model with $n$ firms offering their employees the tournament-type contracts. Optimal wage offers are derived. Section 4 analyzes the findings obtained from the theoretical model. Section 5 is concluding remarks.

\section{Literature Review}

The vast literature on compensation structure for top executives has spawned predominantly from the pioneering work of Lazear and Rosen (1981) [6]. For most part, this literature assumes that the decision-making unit in the tournament models is the risk-neutral individual who responds to wage spread between the winning and losing prizes strategically with an intention to win the game.

It is well documented that both executive pay and the pay gap between executive ranks is positive influence to the firm performance, which predicts that individuals' initial response to higher wage gap is positive. Many studies show that executive compensation exhibits a skewed distribution toward the top of the firm, with the wage spread between the CEO and the second-tier executives being the largest (Main, O’Reilly, and Wade, 1993; Eriksson, 1999; Bognanno, 2001; 
Conyon, Peck, and Sadler, 2001) [7] [8] [9] [10]. Consequently, wage offers can be a useful instrument for firms in motivating individuals to increase output-enhancing activities and/or to reduce unproductive behaviors. As is well known, the existence of industrial politics often leads firms to reduce wage spread since bad behavior (e.g., sabotage) can be triggered by an uneven distribution between the winning and losing prizes (Lazear, 1989) [11]. Thus, optimal wage spread then is a consequence of firm's intention to strike a balance between these two offsetting activities.

Under circumstances in which it is costly to monitor individual outputs as in the case of top-rank executives, the tournament-type compensation scheme provides proper incentives for them to work hard for advancement and promotion. By assuming perfect competition and risk-neutral agents, tournament contracts are proven to be as efficient as piece rate. This strand of research assumes perfect competition in the output market. Therefore, it permits us to focus on factors that are internal to the firm in wage determination. As such, external factors such as output market conditions have largely been ignored. With this in mind, our contribution is to provide a unified model that integrates the effect of market structure into the conventional tournament model.

The importance of taking market structure into account is two fold. First, the market structure changes the level of output firms wish to produce and their profitabilities, thereby affecting firm's ability to pay and consequently their wage offers. In effect, higher market concentration implies higher profits for each firm, which will consequently enhance firm's ability to pay. Higher market concentration would also mean that each firm ends up producing more. The question that needs to be answered is how well should firms motivate their employees? The answer hinges on the relative costs associated with effort and sabotage. If sabotage is cheaper to use for the players, higher wage gap will trigger more sabotage and therefore, a low output results. Obviously, this serves well for firms in a more competitive industry since each firm wishes to produce less. Conversely, players are more likely to rely on effort if sabotage becomes more expensive. Offering the winner more is not the way to go since firms in a more competitive market structure would wish to produce less. In short, the market structure plays an important role in determining firm's wage policy. Secondly, markets are far from being perfectly competitive in most cases. For example, the Herfindah-Hirschman Indices (HHI) among 1145 publicly listed companies in Shanghai and Shenzhen Stock Exchange in 2013 range from 0.0274 to 0.7634 across 58 industries (Chen, 2014) [12]. For industries with high HHI, market concentrations are expected to produce non-marginal effects not only on executive pay but also the pay gap between executive ranks.

Some studies have already done to analyze the relationship between the executive compensation dispersion and the product market. Lin (2008) [13] makes a big effort to study the relationship between the internal labor market and the product market by employing product price as the proxy indicator for the market structure. The main findings show that the wage dispersion will decrease 
when the product price increases, vice versa. Cardullo et al. (2011) [14] proposes variance and Gini Coefficient will change in the opposite direction with the competition intensity of product market. In intuition, as the wage gap continues to increase beyond some critical cutoff point, individuals will find it beneficial to rely on sabotage against their rivals eventually since effort is getting too "expensive" to use. That is, individual performance in relation to wage gap is an inverse $\mathrm{U}$-shaped function. This wage-performance relationship will then be taken into account in firm's decision making process as they play a Cournot-Nash game against their rivals in the output market. It turns out that optimal wage dispersion is widened as the output market moves away from monopoly. Further increase in market competitiveness, firms would reduce the wage gap between the winning and losing prizes. The intuition behind this is natural but the theoretical model should be set and analyzed to verify the relationship between the executive compensation dispersion and market structure.

\section{Modeling}

Consider an industry with $\mathrm{n}$ identical firms producing a homogeneous good and competing against each other in a Cournot-Nash fashion. Outputs are produced by using labor. For simplicity, we assume that each firm (firm $i$, say) hires two identical managers, denoted by $j$ and $k$. Managers are offered the tournament-type compensation in which the winner gets $w_{i}$ and the loser receives zero. This winner-take-all compensation scheme is not uncommon for top executives or in professional sports. One may think of this being a result of normalization. As such, $w$ represents wage dispersion between the winner and the loser.

The game consists of two stages. In stage 1 , firms play a Cournot-Nash game by setting their outputs. This is done through their wage offers to properly motivate their employees so that a desirable level of outputs can be produced. In stage 2, players respond to wage offers by allocating their time endowment between two activities: effort and sabotage. It should be emphasized that in most tournament models, wage offers are purely dictated by the incentive issue with intention to properly motivate their employees. This line of research primarily focuses on factors that are internal to the firm. Our model deviates from these models in one important aspect. Specifically, since firms are connected through a common demand function, the interactions among firms would therefore produce non-marginal impacts on wage determinations. In other words, our present model takes into account not only the incentive responses from employees that are internal to the firm, but also the interactions among firms that are driven by external forces.

Following Lazear and Rosen (1981) and Lazear (1989) [6] [11], manager $j \mathrm{~s}$ output is assumed to take the following form:

$$
q_{j}=e_{j}-\theta_{k}+\varepsilon_{i}, j, k=1,2
$$

where $e_{j}$ and $\theta_{k}$ are the effort level chosen by $j$ and the level of sabotage by $k$. 
is output is subject to some random disturbances $e_{j}$ where $e_{j}$ is distributed according $h\left(\varepsilon_{j}\right)^{1}$. Assume that $E\left(\varepsilon_{j}\right)=0$ and $\operatorname{Var}\left(\varepsilon_{j}\right)=\sigma^{2}$. Note that $\varepsilon_{j}$ is the idiosyncratic shock that affects managers' output in an additive manner and is assumed to be individual specific.

Manager $j$ wins the game if

$$
e_{j}-e_{k}-\theta_{k}+\theta_{j}>\varepsilon_{k}-\varepsilon_{j}
$$

Let $\varepsilon=\varepsilon_{k}-\varepsilon_{j}$, where $E(\varepsilon)=0$ and $\operatorname{Var}(\varepsilon)=2 \sigma^{2}$. Thus, manager $j$ s probability of winning the match is

$$
\rho_{j}=\operatorname{prob}\left(\varepsilon<e_{j}-e_{k}-\theta_{k}+\theta_{j}\right)=H\left(e_{j}-e_{k}-\theta_{k}+\theta_{j}\right)
$$

where $H(\bullet)$ is the distribution function. Given that it is a stage game, the backward induction is proper, beginning with stage-2 game.

Stage 2: Manager $j$ solves the following maximization problem, given by

$$
\max _{\left\{e_{j}, \theta_{j}\right\}} E U_{j}=\rho_{j} w_{j}-C\left(e_{j}, \theta_{j}\right)
$$

where $C\left(e_{j}, \theta_{j}\right)$ is the costs associated with $e_{j}$ and $\theta_{j}$ with $\partial C / \partial e_{j}>0$ and $\partial C / \partial \theta_{j}>0$. The solution is determined by

$$
\begin{aligned}
& w_{i} H^{\prime}\left(e_{j}-e_{k}-\theta_{k}+\theta_{j}\right)=\partial C / \partial e_{j} \\
& w_{i} H^{\prime}\left(e_{j}-e_{k}-\theta_{k}+\theta_{j}\right)=\partial C / \partial \theta_{j}
\end{aligned}
$$

By symmetry,

$$
\begin{aligned}
& e=e_{j}=e_{k}=e\left(w_{i}\right) \\
& \theta=\theta_{j}=\theta_{k}=\theta\left(w_{i}\right)
\end{aligned}
$$

Substituting these into (2) and (3), we obtain

$$
\begin{gathered}
e^{\prime}\left(w_{i}\right)=H^{\prime}(0)\left[\partial^{2} C / \partial \theta^{2}-\partial^{2} C / \partial e \partial \theta\right] / D \\
\theta^{\prime}\left(w_{i}\right)=H^{\prime}(0)\left[\partial^{2} C / \partial e^{2}-\partial^{2} C / \partial e \partial \theta\right] / D \\
q_{j}^{\prime}\left(w_{i}\right)=e^{\prime}\left(w_{i}\right)-\theta^{\prime}\left(w_{i}\right)=H^{\prime}(0)\left[\partial^{2} C / \partial \theta^{2}-\partial^{2} C / \partial e^{2}\right] / D
\end{gathered}
$$

where $D=\partial^{2} C / \partial e^{2} \cdot \partial^{2} C / \partial \theta^{2}-\left(\partial^{2} C / \partial e \partial \theta\right)^{2}>0^{2}$.

Stage 1: Firm $i$ makes a wage offer to managers $j$ and $k$ with profits in mind. In what follows, we should that firm's wage offers depend on the output market structure. As shown below, the output market condition imposes an additional constraint on firm's offer to its employees. Without loss of generality, assume that the market demand is linear:

$$
P=A-B Q
$$

where $A>0, B>0$ and $Q=\sum_{i=1}^{n} Q_{i}$ is the total output produced by $\mathrm{n}$ firms all together.

Since managers and firms are symmetrical, one can easily verify that $Q_{i}\left(w_{i}\right)=2\left[e\left(w_{i}\right)-\theta\left(w_{i}\right)\right]$ and $\sum_{l \neq i} Q_{l}\left(w_{l}\right)=2(n-1)\left[e\left(w_{l}\right)-\theta\left(w_{l}\right)\right]$.

${ }^{1}$ Normalization with unit properly chosen allows us to avoid output being negative.

${ }^{2}$ The second-order condition is assumed to be satisfied. 
Given this, firm $i$ set $w_{i}$ to maximize the profit

$$
\begin{aligned}
& E\left(\pi_{i}\right)=E\left[\left(A-B \sum_{i=1}^{n} Q_{i}\right) Q_{i}-w_{i}\right] \\
& =\left\{A-2 B\left[e\left(w_{i}\right)-\theta\left(w_{i}\right)\right]-\sum_{l \neq i} 2 B\left[e\left(w_{l}\right)-\theta\left(w_{l}\right)\right]\right\}\left[e\left(w_{i}\right)-\theta\left(w_{i}\right)\right]-w_{i}
\end{aligned}
$$

giving $w_{l}, \quad l=1,2, \cdots, i-1, i+1, \cdots, n$.

The first-order conditions are

$$
\begin{gathered}
A-4 B\left[e^{\prime}\left(w_{i}\right)-\theta^{\prime}\left(w_{i}\right)\right]-\left[e^{\prime}\left(w_{i}\right)-\theta^{\prime}\left(w_{i}\right)\right] \sum_{l \neq i} 2 B\left[e\left(w_{l}\right)-\theta\left(w_{l}\right)\right]-1=0 \\
i=1,2, \cdots, n
\end{gathered}
$$

By symmetry, the Cournot-Nash equilibrium must be such that $w=w_{i}$ for all $i$. Thus, Equation (7) can be rewritten as

$$
A-\{4 B+2(n-1)[e(w)-\theta(w)]\}\left[e^{\prime}(w)-\theta^{\prime}(w)\right]-1=0
$$

yielding

$$
w^{*}=w(n)
$$

Assume that the second-order condition for profit maximization is satisfied, i.e., $\partial^{2} E \pi_{i} / \partial w^{2}<0$.

The product market structure is related to the market competition situation, no matter the amount of firms or the differentiation of product. In this paper, the number of firms existing in the same market is considered as the proxy indicator to show the competition situation. It is straightforward to obtain

$$
\mathrm{d} w / \mathrm{d} n=2[e(w)-\theta(w)]\left[e^{\prime}(w)-\theta^{\prime}(w)\right] / \partial^{2} E \pi_{i} / \partial w^{2}
$$

\section{Analysis}

According to the results deducted from theoretical model (see Equations (4), (5) and (6)), it is easy to find that high wage dispersion will lead to higher (lower) performance (i.e., $\left.q_{j}^{\prime}\left(w_{i}\right)>(<) 0\right)$ if $\partial^{2} C / \partial \theta^{2}>(<) \partial^{2} C / \partial e^{2}$. This gives proposition 1.

Proposition 1. Managers produce more (less) in response to higher wage dispersion if $\partial^{2} C / \partial \theta^{2}>(<) \partial^{2} C / \partial e^{2}$.

Proof:

Since $q_{j}^{\prime}\left(w_{i}\right)=e^{\prime}\left(w_{i}\right)-\theta^{\prime}\left(w_{i}\right)=H^{\prime}(0)\left[\partial^{2} C / \partial \theta^{2}-\partial^{2} C / \partial e^{2}\right] / D, \quad H^{\prime}(0)>0$, $D>0, q_{j}^{\prime}\left(w_{i}\right)>0$, when $\partial^{2} C / \partial \theta^{2}-\partial^{2} C / \partial e^{2}>0$, and $q_{j}^{\prime}\left(w_{i}\right)<0$, when $\partial^{2} C / \partial \theta^{2}-\partial^{2} C / \partial e^{2}<0$.

Since $q_{j}^{\prime}\left(w_{i}\right)$ is the product quantity function of wage dispersion, $q_{j}^{\prime}\left(w_{i}\right)>0$ means workers will produce more when the wage dispersion increases, vice versa.

Proposition 1 shows if the cost of sabotage increases more rapidly relative to that of effort, managers are more likely to use a productive mean (i.e., effort) ${ }^{3}$ See the proof below. 
than an unproductive one (i.e., sabotage) to achieve their goal of winning a match. But if the converse is true, then managers are more inclined to rely on sabotage than effort. In short, the relative convexities of the cost function with respect to and determine managers' responses to pay spread between the winning and losing prizes.

In the presence of sabotage, widening wage gap may produce an undesirable outcome, particularly when the cost associated with sabotage is lower-a result that provides a justification for pay equality. The question of whether higher wage dispersion will lead to a better or worse performance for a player is hard to observe since it is complex issue related to managerial psychology and corporate culture, but the related empirical studies (Chen, 2010) [15] shows that higher wage gap will lead to a better performance when $w$ is relatively small. As $w$ increases beyond some critical cutoff, higher wage gap can produce an adverse effect on worker's overall performance. That is, $q_{j}\left(w_{i}\right)$ is concave from below (i.e., inverse U-shaped).

Proposition 2. Optimal wage dispersion increases (decreases) with $\mathrm{n}$ if $\partial^{2} C / \partial \theta^{2}<(>) \partial^{2} C / \partial e^{2}$.

Proof:

Since $\mathrm{d} w / \mathrm{d} n=2[e(w)-\theta(w)]\left[e^{\prime}(w)-\theta^{\prime}(w)\right] / \partial^{2} E \pi_{i} / \partial w^{2}, \partial^{2} E \pi_{i} / \partial w^{2}<0$, then, $\mathrm{d} w / \mathrm{d} n$ changes in the opposite direction with $2[e(w)-\theta(w)]\left[e^{\prime}(w)-\theta^{\prime}(w)\right]$.

Since the quantity of product is potentially assumed to be bigger than zero (otherwise, the firm should be shut down), $e(w)-\theta(w)>0$ then, $\mathrm{d} w / \mathrm{d} n$ changes in the opposite direction with $\left[e^{\prime}(w)-\theta^{\prime}(w)\right]$.

Since $e^{\prime}\left(w_{i}\right)-\theta^{\prime}\left(w_{i}\right)>(<) 0$ if $\partial^{2} C / \partial \theta^{2}>(<) \partial^{2} C / \partial e^{2}$ from Proposition 1, then, $\mathrm{d} w / \mathrm{d} n>0$, if $e^{\prime}\left(w_{i}\right)-\theta^{\prime}\left(w_{i}\right)<0$ when $\partial^{2} C / \partial \theta^{2}>\partial^{2} C / \partial e^{2} \quad$ and $\mathrm{d} w / \mathrm{d} n<0$, if $e^{\prime}\left(w_{i}\right)-\theta^{\prime}\left(w_{i}\right)>0$ when $\partial^{2} C / \partial \theta^{2}<\partial^{2} C / \partial e^{2}$.

The results imply the optimal wage dispersion increases (decreases) with $\mathrm{n}$ if $\partial^{2} C / \partial \theta^{2}<(>) \partial^{2} C / \partial e^{2}$.

This proposition says that optimal wage gap is sensitive to the output market condition. The intuition is straightforward. Market competition reduces outputs each firm produces. When the cost structure is such that $\partial^{2} C / \partial \theta^{2}<\partial^{2} C / \partial e^{2}$, managers are more likely to rely on sabotage since it is cheaper to use. In this case, higher wage offer to the winner will likely trigger more output loss. This serves well for firms facing more competition since they are cutting back on production. Conversely, if $\partial^{2} C / \partial \theta^{2}>\partial^{2} C / \partial e^{2}$ holds, higher wage gap induces more effort relative to sabotage and firm's output increases as a result. This does not sit well with firms when market becomes more competitive.

To win a match, either effort or sabotage can be equally effective. However, effort is often considered by most as a more legimate way of winning a game, which is probably the case for doves. Put differently, effort and sabotage are different in managers' eyes. If so, one may write $C=e^{2} / 2+b \theta^{2} / 2$, where $b>1$ captures the situation in which managers feel uneasy about sabotage. In this case, 
$\partial^{2} C / \partial \theta^{2}>\partial^{2} C / \partial e^{2}$, implying that $\mathrm{d} w / \mathrm{d} n<0$. This, firms will offer lower wage spread (i.e., lower $w$ ) as the market structure becomes more competitive (i.e., lower $n$ ). Conversely, if players are hawks (who are aggressive and perhaps enjoy doing sabotage), then $b<1$. In this case, $\partial^{2} C / \partial \theta^{2}<\partial^{2} C / \partial e^{2}$, implying that $\mathrm{d} w / \mathrm{d} n>0$. This results in higher wage spread as the market structure becomes more competitive.

\section{Concluding Remarks}

Executive compensation becomes more and more useful since it is considered as a managerial instrument to motivate top managers and consequently improve firm performance in China. Based on the findings in this paper, it seems clearly that optimal executive compensation dispersion will be affected by the product market structure. It implies the competition situation should be taken into account when the firms try to make compensation incentive policies. What's more, the relationship between the wage gap and product market structure depends on the cost of effort and sabotage for executives. When executives like to compete with each other without feeling guilty to sabotage others, the optimal compensation dispersion should be widened when the market become more crowded. Conversely, if executives prefer productive activities (i.e., effort) to improve their own performance, the compensation dispersion will get narrower. The main findings in this paper mean different firms with different executives should take different incentive compensation policies under different market structure and show more clearly that product market structure (competition situation) should be taken into account well when the incentive policies are made. What's more, cost of sabotage to effort is a factor which may make the relationship between executive compensation dispersion and product market structure change. That may be the reason why some opposite executive compensation schemes can work well at the same time in the real business world. In the future study, more indicators such as differentiation and price should be used to show the robustness of the results obtained from this study.

\section{Acknowledgements}

Ding Chen acknowledges the financial support from National Social Science Research Program (Item No. 18VSJ094), the Scientific Research Program Funded by Shaanxi Provincial Education Department (Item No. 16JK1584) and Innovation and Practice Training Program for Graduated Students of Xi'an Shiyou University (Item No. YCS17212062).

\section{Conflicts of Interest}

The authors declare no conflicts of interest regarding the publication of this paper.

\section{References}

[1] Mengistae, T. and Xu, L.C. (2004) Agency Theory and Executive Compensation: 
The Case of Chinese State-Owned Enterprises. Journal of Labor Economics, 22, 615-637. https://doi.org/10.1086/383109

[2] Dong, X.Y. (2005) Wage Inequality and Between-Firm Wage Dispersion in the 1990s: A Comparison of Rural and Urban Enterprises in China. Journal of Comparative Economics, 33, 664-687. https://doi.org/10.1016/j.jce.2005.08.002

[3] Korzec, M. (1992) Labor and the Failure of Reform in China. St. Martin's, New York. https://doi.org/10.1007/978-1-349-11804-5

[4] Appleton, S., Song, L. and Xia, Q. (2005) Has China Crossed the River? The Evolution of Wage Structure in Urban China during Reform and Retrenchment. Journal of Comparative Economics, 33, 644-663. https://doi.org/10.1016/j.jce.2005.08.005

[5] Lin, Y.F., Liao, Y.C. and Chang, K.C. (2011) Firm Performance, Corporate Governance and Executive Compensation in High-Teck Business. Total Quality Management, 2, 159-172. https://doi.org/10.1080/14783363.2010.530786

[6] Lazear, E.P. and Rosen, S. (1981) Rank-Order Tournament as Optimum Labor Contracts. Journal of Political Economy, 89, 841-864.

https://doi.org/10.1086/261010

[7] Main, B., Charlys, G.M., O’Reilly, A. and Wade, J. (1993) Top Executive Pay: Tournament or Teamwork? Journal of Labor Economics, 11, 606-628. https://doi.org/10.1086/298309

[8] Eriksson, T. (1999) Excutive Compensation and Tournament Theory: Empirical Tests on Danish Data. Journal of Labor Economics, 17, 262-280. https://doi.org/10.1086/209920

[9] Bognanno, M. (2001) Corporate Tournaments. Journal of Labor Economics, 19, 290-315. https://doi.org/10.1086/319562

[10] Conyon, M.J., Peck, S.I. and Sadler, G.V. (2001) Corporate Tournaments and Executive Compensation: Evidence from the U.K. Strategic Management Journal, 22, 805-815. https://doi.org/10.1002/smj.169

[11] Lazear, E.P. (1989) Pay Equality and Industrial Politics. Journal of Political Econo$m y$, 97, 561-580. https://doi.org/10.1086/261616

[12] Chen, D. (2014) Executive Compensation Dispersion, Product Market Strucuture and Firm Performance. Chinese Social Science Publishing, Beijing.

[13] Lin, M.-J. (2008) External Market Condition and Tournaments-Theory and Evidence. Economic Letters, 99, 75-78. https://doi.org/10.1016/j.econlet.2007.05.034

[14] Cardullo, G. (2011) The Distributive and Welfare Effects of Product and Labour Market Deregulation. Labour Economics, 18, 205-217. https://doi.org/10.1016/j.labeco.2010.10.003

[15] Chen, D. and Zhang, S. (2010) The Study on The Inverse-U Shaped Relationship between Wage Gap and Firm Performance-Theoretical Model and Empirical Exploration. Nankai Economics Review, 5, 35-45. 